University of Nebraska - Lincoln

DigitalCommons@University of Nebraska - Lincoln

1997

\title{
ASSOCIATION BETWEEN PLASMA HOMOCYSTEINE, VITAMIN STATUS, AND EXTRACRANIAL CAROTID-ARTERY STENOSIS IN THE FRAMINGHAM STUDY POPULATION
}

\author{
Jacob Selhub \\ Jean Mayer USDA Human Nutrition Research Center on Aging \\ Paul F. Jacques \\ Jean Mayer USDA Human Nutrition Research Center on Aging \\ Andrew G. Bostrom \\ Framingham Heart Study, National Heart, Lung and Blood Institute \\ Ralph B. D'Agostino \\ Boston University \\ Peter W. F. Wilson \\ Framingham Heart Study, National Heart, Lung and Blood Institute \\ See next page for additional authors \\ Follow this and additional works at: https://digitalcommons.unl.edu/publichealthresources \\ Part of the Public Health Commons
}

Selhub, Jacob; Jacques, Paul F.; Bostrom, Andrew G.; D'Agostino, Ralph B.; Wilson, Peter W. F.; Belanger, Albert J.; O'Leary, Daniel H.; Wolf, Philip A.; Rush, David; Schaefer, Ernst J.; and Rosenberg, Irwin H., "ASSOCIATION BETWEEN PLASMA HOMOCYSTEINE, VITAMIN STATUS, AND EXTRACRANIAL CAROTIDARTERY STENOSIS IN THE FRAMINGHAM STUDY POPULATION" (1997). Public Health Resources. 205. https://digitalcommons.unl.edu/publichealthresources/205 


\section{Authors}

Jacob Selhub, Paul F. Jacques, Andrew G. Bostrom, Ralph B. D'Agostino, Peter W. F. Wilson, Albert J.

Belanger, Daniel H. O'Leary, Philip A. Wolf, David Rush, Ernst J. Schaefer, and Irwin H. Rosenberg 


\section{HOMOCYSTEINE \\ METABOLISM: FROM \\ BASIC SCIENCE TO \\ CLINICAL MEDICINE}

Editors

Ian Graham, MD

THE ADELAIDE HOSPITAL

TRINITY COLLEGE

DUBLIN

IRELAND

Helga Refsum, MD

UNIVERSITY OF BERGEN

DEPARTMENT OF CLINICAL BIOLOGY

BERGEN

NORWAY

Irwin H. Rosenberg, MD

JEAN MAYER USDA HUMAN NUTRITION RESEARCH

CENTER ON AGING AT TUFTS UNIVERSITY

BOSTON, MA

USA

Per Magne Ueland, MD

UNIVERSITY OF BERGEN

DEPARTMENT OF CLINICAL BIOLOGY

BERGEN

NORWAY

Scientific Editor:

Jill M. Shuman, MS, RD, ELS

TUFTS UNIVERSITY SCHOOL OF

NUTRITION SCIENCE AND POLICY MEDFORD, MA

$$
\text { USA }
$$

Kluwer Academic Publishers

BOSTON DORDRECHT LONDON 
Jacob Selhub

Jean Mayer USDA Human Nutrition Research Center on Aging

Tufts University

Boston, MA, USA

Paul F. Jacques

Jean Mayer USDA Human Nutrition Research Center on Aging

Tufts University

Boston, MA, USA

Andrew G. Bostom

Framingham Heart Study

National Heart, Lung and Blood Institute

Framingham, MA, USA

Ralph B. D'Agostino

Department of Mathematics

Statistics and Consulting Unit

Boston University

Boston, MA, USA

Peter W.F. Wilson

Framingham Heart Study

National Heart, Lung, and Blood Institute

Framingham, MA, USA

Albert J. Belanger

Department of Mathematics

Statistics and Consulting Unit

Boston University

Boston, MA, USA
Daniel H. O'Leary

Department of Radiology

Geisinger Medical Center

Danville, PA, USA

Philip A. Wolf

Department of Neurology

Boston University School of Medicine

Boston, MA, USA

David Rush

Jean Mayer USDA Human Nutrition Research Center on Aging

Tufts University

Boston, MA, USA

Ernst J. Schaefer

Jean Mayer USDA Human Nutrition Research Center on Aging

Tufts University

Boston, MA, USA

Irwin H. Rosenberg

Jean Mayer USDA Human Nutrition Research Center on Aging

Tufts University

Boston, MA, USA 


\title{
14. ASSOCIATION BETWEEN PLASMA HOMOCYSTEINE, VITAMIN STATUS, AND EXTRACRANIAL CAROTID-ARTERY STENOSIS IN THE FRAMINGHAM STUDY POPULATION
}

\author{
Jacob Selhub, Paul F. Jacques, Andrew G. Bostom, Ralph B. D'Agostino, \\ Peter W.F. Wilson, Albert J. Belanger, Daniel H. O'Leary, Philip A. Wolf, David Rush, \\ Ernst J. Schaefer, and Irwin H. Rosenberg
}

\section{Summary}

Recent epidemiologic studies suggest that elevated homocysteine concentrations in plasma represent a risk factor for vascular disease and stroke. In the present study, we analyzed plasma samples from the 20th biannual examination of the Framingham Heart Study cohort to determine distribution of plasma homocysteine concentrations, with emphasis on relationships to vitamins that are involved in homocysteine metabolism and prevalence of carotid artery stenosis. Results showed that homocysteine was positively correlated with age. After controlling for age and sex, homocysteine exhibited strong inverse correlation with plasma folate, and weaker correlations with plasma vitamin $\mathrm{B}_{12}$ and pyridoxal$5^{\prime}$-phosphate. Homocysteine was also inversely correlated with intakes of folate and vitamin $B_{6}$, but not vitamin $B_{12}$. Prevalence of high homocysteine $(>14 \mu \mathrm{mol} / \mathrm{L})$ was $29.3 \%$ in this cohort, and inadequate plasma concentrations of one or more B vitamins appeared to contribute to $67 \%$ of the cases of high homocysteine. After adjustment for sex, age, HDL cholesterol, systolic blood pressure, and cigarette smoking, the prevalence of carotidartery stenosis $\geq 25 \%$ was $43 \%$ in men and $34 \%$ in women with an odds ratio of 2.0 for individuals in the highest homocysteine quartile, compared with those in the lowest quartile $(p<0.001)$. Plasma concentrations of folate and pyridoxal- $5^{\prime}$-phosphate and folate intake were inversely associated with extracranial carotid stenosis after adjustment for age, sex, and other risk factors. These data indicate that hyperhomocysteinemia is prevalent $(30 \%)$ in this aged population, and that it is associated with increased risk of extracranial carotid-artery stenosis. Insufficient levels of folate, and, to a lesser extent, vitamin $B_{6}$, appear to predict part of this elevated risk through their role in homocysteine metabolism.

\section{Introduction}

In recent years, there have been growing indications suggesting that moderate elevations of homocysteine in plasma are a risk factor for occlusive vascular disease and stroke [1-3]. A literature survey by Ueland et al. [1] identified a total of 21 studies involving more than 1,500 patients with occlusive (cardiovascular, peripheral, and cerebrovascular) vascular disease and more than 1,500 respective controls. Sixteen of these studies reported significantly higher mean plasma homocysteine concentrations in patients than in respective controls $(p<0.05$ to $<0.001)$. The mean patient/control homocysteine ratio according to this survey was 1.31 , which indicates that the elevation of homocysteine in these patients is mild and certainly not as severe as that seen in homocystinuric patients. 


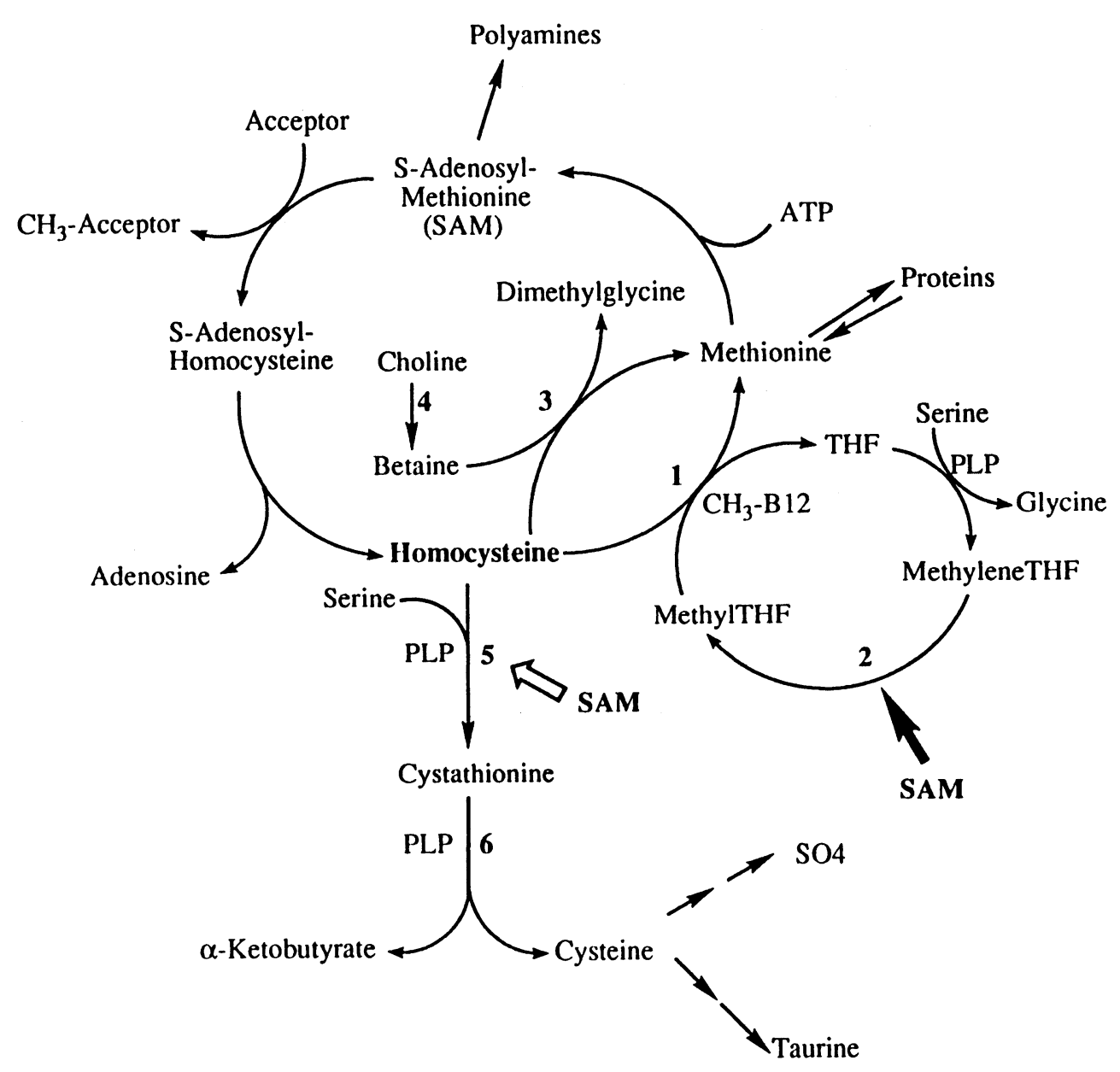

Our interest in homocysteine was prompted by the possibility that plasma homocysteine may serve as an indicator of the status and perhaps the intake of a number of vitamins, including folic acid, vitamin $B_{12}$, and vitamin $B_{6}$. This possibility derived from the large number of studies indicating that methionine metabolism is tightly regulated [4-6], and from other studies showing that deficiencies in the above vitamins is often associated with hyperhomocysteinemia [7-20].

Homocysteine is a sulfur amino acid whose metabolism is at the intersection of two metabolic pathways: remethylation and transsulfuration (fig. 14-1). In remethylation, homocysteine acquires a methyl group from N-5-methyltetrahydrofolate (MTHF) or from betaine to form methionine. The reaction with MTHF occurs in all tissues and is vitamin $B_{12}$-depen-
FIGURE 14-1. Homocysteine metabolism: 1, methylenetetrahydrofolate reductase; 2 , cystathionine- $\beta$-synthase; 3 , cystathionase; THF, tetrahydrofolate; PLP, pyridoxal-5'phosphate; and $\mathrm{CH} 3-\mathrm{B}_{12}$, methylated vitamin $\mathrm{B}_{12}$.

dent, while the reaction with betaine is confined mainly to the liver and is vitamin $B_{12}$-independent. A considerable proportion of methionine is then activated by ATP to form S-adenosylmethionine (SAM). SAM serves primarily as a universal methyl donor to a variety of acceptors, including guanidinoacetate, nucleic acids, neurotransmitters, phospholipids, and hormones. S-adenosylhomocysteine (SAH), the byproduct of these methylation reactions, is subsequently hydrolyzed, thus regenerating homocysteine, which then becomes available to start a new cycle of methyl-group transfer. 
In the transsulfuration pathway, homocysteine condenses with serine to form cystathionine in an irreversible reaction catalyzed by the pyridoxal- 5 'phosphate (PLP)-containing enzyme, cystathionine $\beta$-synthase. Cystathionine is hydrolyzed by a second PLP-containing enzyme, $\gamma$-cystathionase, to form cysteine and $\alpha$-ketobutyrate. Excess cysteine is oxidized to taurine and inorganic sulfates or excreted in the urine. Thus, in addition to the synthesis of cysteine, this transsulfuration pathway effectively catabolizes excess homocysteine that is not required for methyl transfer. It is important to note that since homocysteine is not a normal dietary constituent, the sole source of homocysteine is methionine.

Studies of the regulation of homocysteine metabolism have demonstrated that the utilization of homocysteine molecules by the transsulfuration and remethylation pathways is nutritionally regulated. Mudd and Poole [21] and Mudd et al. [22] have shown that when the intake of labile methyl groups (i.e., methionine and choline) is modified, the de novo synthesis of methionine methyl groups is affected. When a basal methionine-containing diet was fed, homocysteine moieties were found to cycle through the remethylation pathway approximately 1.5 to 2.0 times before being catabolized through the transsulfuration pathway. When dietary methionine was halved, the number of cycles per homocysteine moiety increased twofold. Conversely, when excess dietary methionine was fed, homocysteine cycling decreased below basal levels. Similar adaptations to changing levels of dietary methionine were observed by Eloranta et al. in rats [23].

This capacity of the body to discriminate between the remethylation and transsulfuration pathways as a way to adapt to varying amounts of methionine in the diet strongly implies the existence of a coordinate regulation between these two pathways. Available experimental evidence, obtained primarily from measurements of enzyme activities in vitro, suggests that this coordination is achieved by at least two mechanisms. The first mechanism is a function of SAM's propensity to act as an allosteric inhibitor of methylenetetrahyrofolate reductase [24] and as an activator of cystathionine $\beta$-synthase [25]. As such an effector, SAM suppresses the synthesis of an important substrate (N-5-methyltetrahydrofolate) required for remethylation and promotes the initial reaction of transsulfuration (cystathionine synthesis). Thus, intracellular SAM concentration is an important determinant of the fate of homocysteine molecules.

The second mechanism by which remethylation and transsulfuration are coordinated consists of the regulation of intracellular SAM concentration itself.
In the liver, SAM synthesis is catalyzed by two enzymes that are peculiar to this organ and that, although immunologically similar, are different in other respects [26-27]. One enzyme, a tetramer of high molecular weight, exhibits a high affinity for methionine and is thought to function at normal physiologic conditions. The second enzyme is a dimer of a lower molecular weight, has a low affinity for methionine, and is thought to function under conditions of high methionine intake. Thus, changes in intracellular methionine, particularly due to dietary intake, will affect the rate of SAM synthesis based on the activity of the SAM synthetase enzymes.

The utilization of SAM also is thought to be regulated specifically by a reaction in which the methyl group of SAM is transferred to the amino group of glycine, forming sarcosine. This reaction is catalyzed by glycine N-methyltransferase (GNMT), which is abundant in the liver and which is strongly inhibited by $\mathrm{N}-5$-methyltetrahydrofolate polyglutamates [29$30]$. Thus, along with intracellular methionine, N-5methyltetrahydrofolate participates in the regulation of intracellular SAM concentrations.

When the two mechanisms of regulation are considered together, the following scenarios can be predicted:

1. When dietary methionine is high, the low molecular weight SAM synthetase will rapidly convert the incoming methionine to SAM. The resulting rise in intracellular SAM concentration will be associated with: a) inhibition of methylenetetrahydrofolate reductase, resulting in suppressed N-5-methyltetrahydrofolate synthesis, thereby allowing the GNMT enzyme to act near full capacity because of suppressed inhibitor (N-5methyltetrahydrofolate) concentration, and b) activation of the cystathionine $\beta$-synthase enzyme, thus increasing the rate of homocysteine catabolism. In this way, homocysteine transsulfuration is promoted over remethylation consistent with the reduced need for de novo methionine synthesis due to the high dietary supply of methionine.

2. Conversely, when the dietary methionine supply is low, SAM concentration would be insufficient for inhibiting methylenetetrahydrofolate reductase, resulting in an elevated rate of N-5methyltetrahydrofolate production. The resulting rise in intracellular N-5-methyltetrahydrofolate concentration will be associated with: a) inhibition of GNMT and thereby conservation of SAM, and b) an increase in the availability of substrate for homocysteine remethylation. Thus, remethylation will be favored over transsulfuration because 
of a concentration of SAM too low to activate the cystathionine $\beta$-synthase enzyme. This is consistent with the increased need for de novo methionine synthesis because of the low dietary input of methionine.

Due to the existence of a cellular homocysteine export mechanism, plasma normally contains a small amount of homocysteine, averaging $10 \mu \mathrm{mol} / \mathrm{L}$ [31,22]. This export mechanism complements the catabolism of homocysteine through transsulfuration; together these mechanisms help maintain low intracellular concentrations of this potentially cytotoxic sulfur amino acid. In hyperhomocysteinemia, plasma homocysteine levels are elevated. Barring kidney malfunction, the occurrence of hyperhomocysteinemia indicates that homocysteine metabolism has in some way been disrupted and that the export mechanism is disposing excess homocysteine into the blood that has accumulated in the cell. This limits intracellular toxicity, but leaves vascular tissue exposed to the possibly deleterious effects of excess homocysteine.

The aims of our study were therefore to: (1) to determine the relationship between plasma homocysteine concentrations and status and intake of folate, vitamin $B_{12}$ and vitamin $B_{6}$; (2) to determine the prevalence of hyperhomocysteinemia; (3) to determine the contribution of vitamin status and intake to the prevalence of hyperhomocysteinemia and; (4) to describe the associations between plasma homocysteine, vitamin status, and intake and prevalence of carotid artery stenosis. This chapter is a summary of our two previous publications [33,34].

\section{Methods}

\section{SUBJECTS}

Participants were members of the original Framingham Heart Study cohort, a population-based sample of 5,209 men and women originally examined in 1948-1952 [35] and followed prospectively to the present to assess the occurrence of vascular disease. This study was based on 1,401 survivors of the original cohort who participated in the 20th biennial examination (1989-1990). Homocysteine and carotid ultrasound measures were available for 1,041 individuals (418 men and 623 women) 67-96 years of age at the time of data collection. Informed consent was obtained from all participants. The protocols for this study were approved by the Human Investigations Review Committee at New England Medical Center and by the Institutional Review Board for Human Research at Boston University Medical Center.

\section{BIOCHEMICAL DETERMINATIONS}

Blood was drawn nonfasting, and plasma total cholesterol and HDL cholesterol were determined in the Framingham Heart Study laboratory using enzymatic methods [36,37]. LDL cholesterol was not determined because the blood samples were taken in a nonfasting state. Plasma samples stored frozen at $-80^{\circ} \mathrm{C}$ were used for the determination of total homocysteine by the method of Araki and Sako [38], plasma folate was determined by a microbial assay using a 96-well plate and manganese supplementation as described by Tamura et al. [39], vitamin $B_{12}$ using a (Magic) radioassay kit from Ciba-Corning (Medfield, MA), and pyridoxal-5'-phosphate by the tyrosine decarboxylase method as described by Camp et al. [40]. Because of insufficient plasma volume, vitamin measures were not available for all subjects.

\section{NUTRIENT INTAKE}

Members of the Framingham cohort received a semiquantitative food frequency questionnaire by mail [31] when they were scheduled for their 20th biennial examination. Subjects returned the completed questionnaire at the time of their examination. Estimated folate and vitamin $B_{6}$ intakes corresponded well to the respective folate and PLP plasma concentrations. Vitamin $B_{12}$ intake was not, however, correlated with plasma vitamin $B_{12}[31,32]$.

\section{MEASUREMENT OF CAROTID STENOSIS}

At the 20th biennial examination, participants underwent a carotid Doppler examination with Ultrasonix, high resolution, real-time scanner equipped with a $7.5 \mathrm{MHz}$ imaging transducer, a 4$\mathrm{MHz}$ pulse wave Doppler transducer, and a $4-\mathrm{MHz}$ continuous wave transducer. For this report, we classified individuals into two categories based on the maximum percent diameter stenosis of the more diseased artery: $0 \%-24 \%$ stenosis or $25 \%-100 \%$ stenosis.

\section{STATISTICAL METHODS}

To describe the associations between plasma homocysteine concentrations and the B vitamins, we grouped subjects into deciles of plasma vitamin concentration and vitamin intake. We calculated the geometric mean plasma homocysteine concentrations in each vitamin decile and plotted these values and their $95 \%$ confidence limits at the median vitamin level within each decile. We adjusted mean homocysteine levels for age, sex, and concentration or intake of the other B vitamins by analysis of covariance 
[43], with all covariates set to their respective sample means. We also adjusted all vitamin intakes for energy [44].

To examine the association between the occurrence of high plasma homocysteine concentrations and these vitamins, we defined high homocysteine as concentrations $>14.0 \mu \mathrm{mol} / \mathrm{L}$ (the 90th percentile for homocysteine among those subjects whose three plasma vitamins levels were above the 70 th percentile). We developed a B-vitamin index to describe the joint relationships of the three vitamins included in these analyses to homocysteine levels. The indices had five categories based on percentile values for each nutrient. We classified individuals with all three vitamins above the 70th percentile into the reference category (category 1). Category 2 included individuals with all three vitamins above the 50th but at least one below the 70th percentile; category 3 included those with at least one vitamin above and one vitamin below the 50th percentile; category 4 included those with all three vitamins below the 50th percentile but at least one above the 30th percentile; and category 5 included individuals with all vitamins below the 30th percentile. We determined mean homocysteine concentration, the prevalence of high homocysteine, the prevalence rate ratio for high homocysteine, and attributable proportion (attributable risk percent [45]) within each vitamin index category. We also estimated population attributable proportion, which represents the proportion of cases with high homocysteine in the population that can be attributed to low plasma vitamin concentrations or vitamin intake.

To graphically describe the relation of homocysteine to stenosis, we classified men and women into quartiles of homocysteine concentration. Within each quartile, we computed the prevalence of carotid stenosis $\geq 25 \%$ and plotted the prevalence estimates at the sex-specific median homocysteine concentration for that quartile. To adjust for other risk factors for carotid stenosis, logistic regression was used with stenosis $\geq 25 \%$ as the dependent variable. Homocysteine quartiles were modeled using indicator variables to represent the three highest quartiles, and relative risk of stenosis for each quartile, compared with the lowest quartile, was estimated as the odds ratio derived as the antilogarithm of the logistic regression coefficients. To examine the association between the nutrition determinants of plasma homocysteine and stenosis, we also divided subjects into quartiles for each vitamin measure and represented them in the regression models as indicator variables using the highest plasma vitamin quartile as the reference category to estimate the relative risk of lower nutrient levels. If not otherwise noted, statistical significance refers to $P$ less than 0.05 .

\section{Results}

\section{HOMOCYSTEINE DISTRIBUTION \\ AND PREVALENCE OF HIGH \\ HOMOCYSTEINE CONCENTRATIONS}

The mean homocysteine concentration for all subjects was $11.9 \mu \mathrm{mol} / \mathrm{L}($ median $=11.6 \mu \mathrm{mol} / \mathrm{L})$. Values ranged from 3.5 to $66.9 \mu \mathrm{mol} / \mathrm{L}$. Homocysteine concentration was higher in men than in women and increased with age (table 14-1). The increase with age remained highly significant $(P<0.001)$ for men and

TABLE 14-1. Mean homocysteine and B vitamin status and intake by age and sex

\begin{tabular}{|c|c|c|c|c|c|c|c|c|c|c|}
\hline \multirow[b]{2}{*}{ Sex } & \multirow[b]{2}{*}{ Age, y } & \multirow[b]{2}{*}{$\mathrm{n}$} & \multirow[b]{2}{*}{$\begin{array}{l}\text { Homocysteine, } \\
\mu \mathrm{mol} / \mathrm{L}\end{array}$} & \multirow[b]{2}{*}{$\begin{array}{l}\text { Homocysteine, } \\
\text { \& Elevated }\end{array}$} & \multicolumn{3}{|c|}{ Plasma concentrations } & \multicolumn{3}{|c|}{ Nutrient intake $/ 4,200 \mathrm{KJ}$} \\
\hline & & & & & $\begin{array}{l}\text { Folate, } \\
\mathrm{nmol} / \mathrm{L}\end{array}$ & $\begin{array}{l}\text { Vitamin } \\
\mathrm{B}_{12} \mathrm{pmol} / \mathrm{L}\end{array}$ & $\begin{array}{l}\mathrm{PLP} \\
\mathrm{nmol} / \mathrm{L}\end{array}$ & $\begin{array}{l}\text { Folate, } \\
\mu g\end{array}$ & $\begin{array}{l}\text { Vitamin } \\
\mathrm{B}_{12} \mu \mathrm{g}\end{array}$ & $\begin{array}{l}\text { Vitamin } \\
\text { B6 } \mathrm{mg}\end{array}$ \\
\hline \multirow[t]{3}{*}{ Men } & $67-74$ & 239 & 11.8 & 25.3 & 9.3 & 265 & 52.6 & 174 & 3.7 & 1.4 \\
\hline & $75-79$ & 110 & 11.9 & 26.7 & 9.5 & 260 & 49.6 & 180 & 3.8 & 1.3 \\
\hline & $80+$ & 108 & 14.1 & 48.3 & 10.0 & 255 & 47.6 & 204 & 4.8 & 1.4 \\
\hline \multicolumn{11}{|c|}{$P$ (for trend } \\
\hline \multirow[t]{3}{*}{ Women } & $67-74$ & 310 & 10.7 & 19.5 & 10.4 & 302 & 59.9 & 214 & 4.0 & 1.6 \\
\hline & $75-79$ & 204 & 11.9 & 28.9 & 10.2 & 289 & 52.2 & 220 & 4.4 & 1.5 \\
\hline & $80+$ & 189 & 13.2 & 41.4 & 9.7 & 290 & 52.1 & 199 & 4.9 & 1.5 \\
\hline \multicolumn{7}{|c|}{$P$ (for trend } & 0.13 & 0.23 & 0.03 & 0.55 \\
\hline$P(\operatorname{sex})$ & $\ldots$ & & 0.003 & 0.09 & 0.19 & 0.001 & 0.08 & $<0.001$ & 0.07 & 0.02 \\
\hline
\end{tabular}


women after adjustment for plasma vitamin concentrations, but the difference between men and women was no longer statistically significant.

We defined high homocysteine as concentrations greater than the 90th percentile among subjects with all plasma vitamin levels $>70$ th percentile $(14.0 \mu \mathrm{mol} / \mathrm{L})$. Prevalence of high homocysteine was $29.3 \%$ for the entire cohort and over $40 \%$ for individuals 80 years of age and older.

\section{Mean Homocysteine Concentration by Vitamin Status and Intake}

\section{FOLATE}

Mean plasma homocysteine concentrations for subjects in the two lowest deciles of plasma folate (below $4.8 \mathrm{nmol} / \mathrm{L}$ ) were 15.6 and $13.7 \mu \mathrm{mol} / \mathrm{L}$. These were significantly greater than the mean for subjects in the highest decile, which was $11.0 \mu \mathrm{mol} / \mathrm{L}(p<0.01)$ (fig. 14-2A). Mean homocysteine concentrations for subjects in the three lowest deciles of folate intake (less than $253 \mu \mathrm{g} /$ day) were $13.7,12.9$, and $13.2 \mu \mathrm{mol} / \mathrm{L}$, respectively, and were significantly greater than the mean for subjects in the highest intake decile, which was $10.4 \mu \mathrm{mol} / \mathrm{L}(p<0.01)$ (fig. $13-3 \mathrm{~A})$.

VITAMIN $B_{12}$

Mean homocysteine concentrations were significantly elevated for subjects in the lowest decile for vitamin B12 relative to subjects in the highest decile $(p<$ 0.01 ). Mean homocysteine concentrations were 15.4 and $10.9 \mu \mathrm{mol} / \mathrm{L}$ for subjects in the lowest and highest vitamin $B_{12}$ deciles (fig. 14-2B). Subjects in the lowest vitamin $B_{12}$ decile had vitamin $B_{12}$ concentrations below $139 \mathrm{pmol} / \mathrm{L}$. Vitamin $\mathrm{B}_{12}$ intake appeared unrelated to mean homocysteine concentration even though subjects in the fifth decile had significantly higher homocysteine concentrations than subjects in the highest decile $(p<0.05)$ (fig. 13-3B).

\section{VITAMIN B 6}

Mean homocysteine concentrations were significantly elevated for subjects in the lowest decile for PLP relative to subjects in the highest decile for this vita$\min (p<0.01)$. Mean homocysteine concentrations were 14.3 and $10.9 \mu \mathrm{mol} / \mathrm{L}$ for subjects in the lowest and highest PLP deciles (fig. 14-2c). Subjects in the lowest decile and PLP concentrations below $18.1 \mathrm{nmol} / \mathrm{L}$. For vitamin $\mathrm{B}_{6}$ intake, mean homocysteine concentrations were significantly elevated in the lowest two deciles $(p<0.01)$ and the third decile $(p<0.05)$. Mean homocysteine concentrations were $13.4,12.4$, and $12.3 \mu \mathrm{mol} / \mathrm{L}$ for subjects in the lowest three deciles; the mean in the highest decile was
$10.1 \mu \mathrm{mol} / \mathrm{L}$ (fig. 14-3c). Subjects in the lowest three intake deciles reported consuming less than $1.75 \mathrm{mg} /$ day.

\section{Homocysteine Concentrations by Overall Vitamin Status}

Mean homocysteine and the prevalence of high homocysteine increased dramatically across categories of the B-vitamin index (table 14-2). Mean homocysteine concentration was $75 \%$ greater in the lowest relative to the highest index categories. The

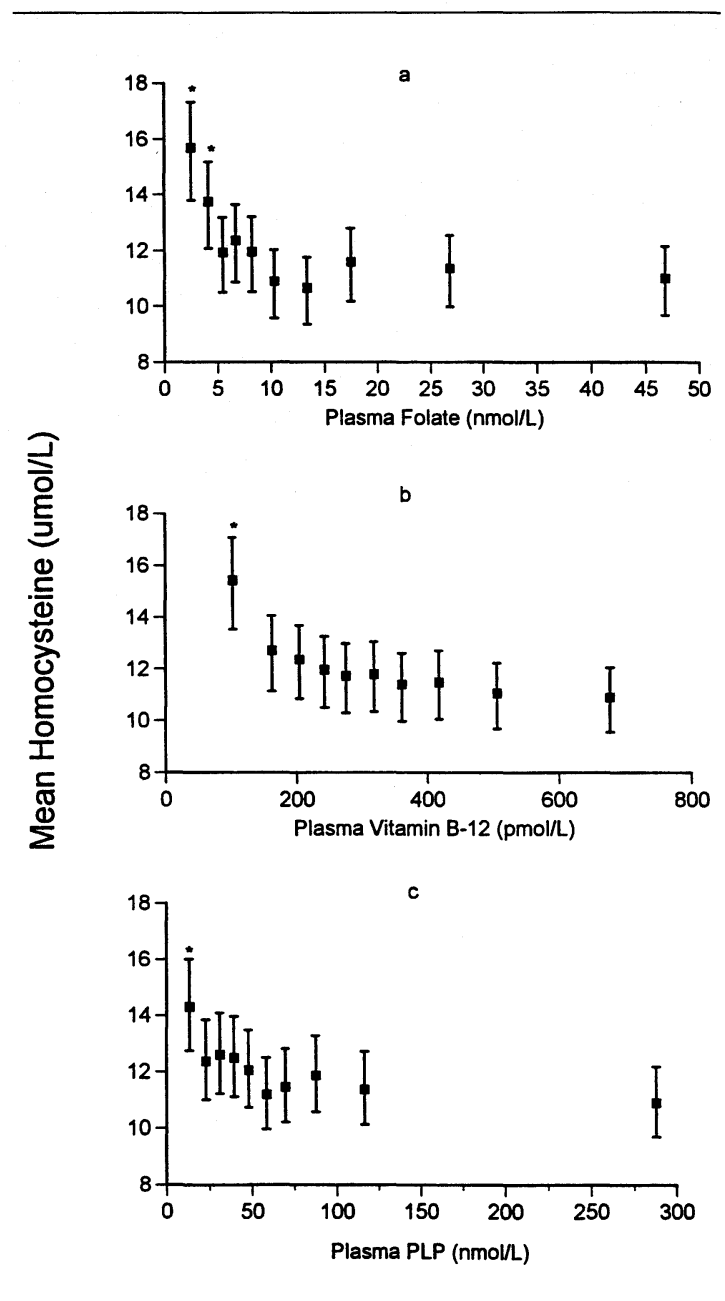

FIGURE 14-2. Mean plasma homocysteine concentrations (and 95\% confidence intervals) by deciles of plasma folate (a), vitamin $\mathrm{B}_{12}$ (b) and PLP (c) concentrations. Means are adjusted for age, sex and other plasma vitamins. (* significantly different from mean in the highest decile $[p<$ 0.011.) 

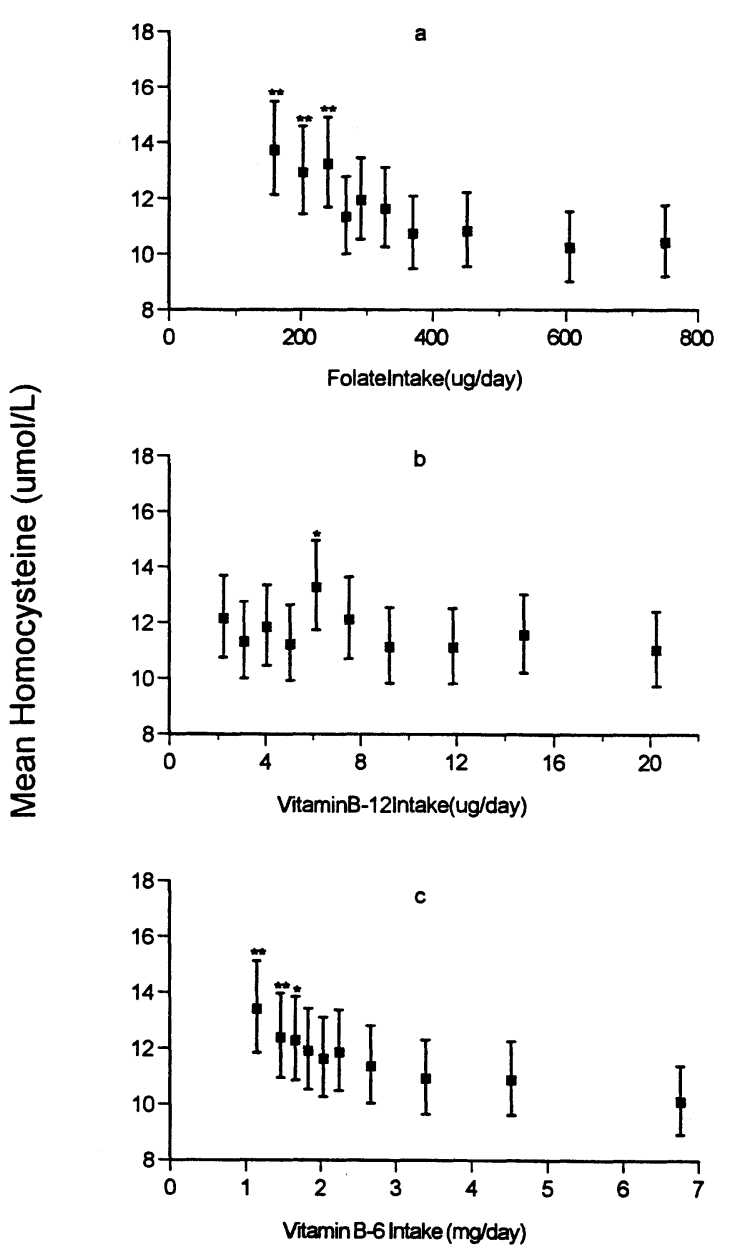

FIGURE 14-3. Mean plasma homocysteine concentrations (and $95 \%$ confidence intervals) by deciles of intake of folate (a), vitamin $\mathrm{B}_{6}$ (b) and vitamin $\mathrm{B}_{12}$ (c). Means are adjusted for age, sex and other vitamin intakes. (*significantly different from mean in the highest decile $[p<0.05]$; $* *$ significantly different from mean in the highest decile $[p<0.01]$.)

TABLE 14-2. Elevated homocysteine concentrations by B vitamin status

\begin{tabular}{|c|c|c|c|c|c|c|c|}
\hline \multicolumn{2}{|c|}{$\begin{array}{l}\text { B vitamin } \\
\text { Index }^{1}\end{array}$} & $\frac{n}{89}$ & $\begin{array}{l}\text { Mean } \\
\text { homocysteine } \\
(\mu \mathrm{mol} / \mathrm{L})\end{array}$ & $\begin{array}{l}\begin{array}{l}\text { Prevalence } \\
(\%)\end{array} \\
10.1\end{array}$ & $\begin{array}{l}\text { Prevalence } \\
\text { rate } \\
\text { ratio }\end{array}$ & $\begin{array}{l}\begin{array}{l}\text { Attributable } \\
\text { percent }\end{array} \\
0.0\end{array}$ & $\begin{array}{l}\begin{array}{l}\text { Population } \\
\text { attributable } \\
\text { percent }\end{array} \\
0.0\end{array}$ \\
\hline Highest & $\begin{array}{l}1 \\
2 \\
3 \\
4\end{array}$ & $\begin{array}{r}89 \\
128 \\
534 \\
144\end{array}$ & $\begin{array}{c}9.4 \\
9.8 \\
11.9^{*} \\
14.9^{*}\end{array}$ & $\begin{array}{l}10.1 \\
12.5 \\
28.7 * \\
52.1^{*}\end{array}$ & $\begin{array}{l}1 \\
1.2 \\
2.8 \\
5.2\end{array}$ & $\begin{array}{r}0.0 \\
19.2 \\
64.8 \\
80.6\end{array}$ & $\begin{array}{r}0.0 \\
1.0 \\
33.7 \\
20.6\end{array}$ \\
\hline Lowest & 5 & 70 & $16.5 *$ & $58.6 *$ & 5.8 & $\begin{array}{l}82.8 \\
\text { (total) }\end{array}$ & $\begin{array}{l}11.6 \\
66.9\end{array}$ \\
\hline
\end{tabular}

\footnotetext{
${ }^{1}$ Index combines plasma folate, vitamin $\mathrm{B}_{12}$ and PLP concentrations: High $(1)=$ all three B vitamins $>70$ th percentile; $2=$ all vitamins $>50$ th, at least $1<$ 70 th percentile; $3=$ vitamins above and below the 50 th percentile; $4=$ all vitamins $<50$ th percentile, at least $1>30$ th percentile; low $(5)=$ all three vitamins $<30$ th percentile.
}

* Significantly different from category $1(P<0.01)$. 
prevalence of high homocysteine was almost sixfold greater among subjects in the lowest index category, compared with subjects in the highest category for plasma index. Sixty-seven percent of the cases of high homocysteine in this cohort of older subjects were associated with at least one vitamin concentration below the 70th percentile. Although the prevalence of high homocysteine was substantially greater in lower vitamin categories ( 4 and 5) than in the middle category, this latter category contributed the largest share of cases of high homocysteine for the index, because it included the largest proportion of the cohort.

\section{Relationship Between Plasma Homocysteine and Prevalence of Extracranial Stenosis}

The prevalence of extracranial carotid stenosis $\geq 25 \%$ was approximately $43 \%$ and $34 \%$ in men and women, respectively. Fig. 14-4 shows the age-adjusted prevalence of stenosis across quartiles of plasma homocysteine levels. In men, the prevalence of stenosis $\geq 25$ percent was $27 \%$ (95\% confidence interval $[17 \%-38 \%])$ in the lowest homocysteine quartile and $58 \%$ (95\% confidence interval [49\%-67\%] in the highest quartiles $(p<0.001)$. The correlation in women was not as striking as that in men; prevalence of stenosis $\geq 25 \%$ ranged from $31 \%$ (95\% confidence interval (24-38\%)) to 39\% (95\% confidence interval, $(31-47 \%))$ across homocysteine quartiles $(p=0.03)$. While the risk of stenosis appeared to increase in the second homocysteine quartile $(9.1-11.3 \mu \mathrm{mol} /$ liter) among men, it did not appear to increase until the third homocysteine quartile $(11.4-14.3 \mu \mathrm{mol} /$ liter) among women. Although the prevalence of stenosis appeared somewhat greater among men than women in the upper quartiles of homocysteine, a test of interaction between sex and homocysteine indicated that the trends for prevalence of stenosis $\geq 25 \%$ were not significantly different for men and women $(p=0.07)$.

The age- and sex-adjusted odds ratios (OR) for men and women combined were significantly increased in the third $(\mathrm{OR}=1.6 ; 95 \%$ confidence interval $[1.1-$ $2.41)$ and fourth $(\mathrm{OR}=2.1 ; 95 \%$ confidence interval [1.5-3.0]) quartiles of homocysteine $(\geq 14.4 \mu \mathrm{mol} /$ liter) relative to the lowest quartile $(\leq 9.1 \mu \mathrm{mol} / \mathrm{liter})$ (table 14-3). Adjustment for other risk factors had little effect on the ORs.

The associations between carotid stenosis and the plasma vitamins are shown in table 14-4. The prevalence of stenosis $\geq 25 \%$ was inversely associated with both folate $\left(P_{\text {trend }}<0.001\right)$ and pyridoxal-5'-phosphate $\left(P_{\text {trend }}=0.03\right)$ after adjustment for age, sex, and other risk factors. The OR for stenosis was 1.9 (95\%

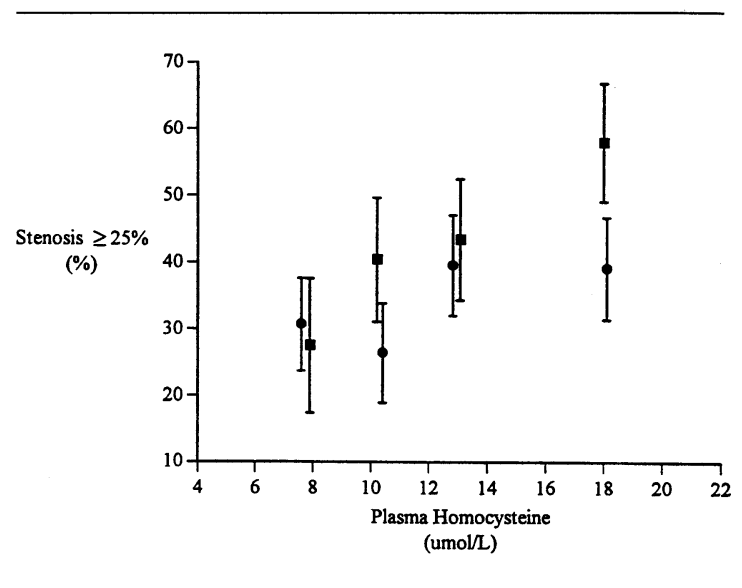

FIGURE 14-4. Age-adjusted prevalence and 95\% confidence limits of maximum extracranial carotid artery diameter stenosis $\geq 25 \%$ by quartile of plasma homocysteine concentration in men (squares) and women (circles). Homocysteine quartile cutoff values were $9.1,11.3$, and $14.3 \mu \mathrm{mol} /$ liter. Test for linear trend: $P<0.001$ for men, $P=0.03$ for women.

TABLE 14-3. Odds ratio of maximal extracranial carotid artery diameter stenosis $\geq 25 \%$ by quartile of plasma homocysteine concentration $(n=1,041)$

\begin{tabular}{|c|c|c|c|c|c|c|}
\hline \multirow{2}{*}{$\begin{array}{l}\text { Homocysteine } \\
\text { quartile }(\mu \mathrm{mol} / \mathrm{L})\end{array}$} & \multicolumn{3}{|c|}{ Age and sex adjusted } & \multicolumn{3}{|c|}{ Multiple risk factor adjustment ${ }^{\ddagger}$} \\
\hline & Odds ratio & $95 \% \mathrm{CI}^{\dagger}$ & $P$-value & Odds Ratio & $95 \% \mathrm{CI}$ & $P$-value \\
\hline$\leq 9.1$ & 1.0 & & & 1.0 & & \\
\hline $9.2-11.3$ & 1.1 & $0.8,1.6$ & 0.60 & 1.1 & $0.8,1.6$ & 0.58 \\
\hline $11.4-14.3$ & 1.6 & $1.1,2.4$ & 0.009 & 1.6 & $1.1,2.3$ & 0.02 \\
\hline$\geq 14.4$ & 2.1 & $1.5,3.0$ & $<0.001$ & 2.0 & $1.4,2.9$ & $<0.001$ \\
\hline$P_{\text {trend }}$ & & & $<0.001$ & & & $<0.001$ \\
\hline
\end{tabular}

${ }^{\dagger} \mathrm{CI}=$ confidence interval.

${ }^{\ddagger}$ Adjusted for sex, age, total/HDL cholesterol ratio, smoking status, and systolic blood pressure. 
TABLE 14-4. Odds ratios of maximal extracranial carotid artery diameter stenosis $\geq 25 \%$ by quartile of plasma vitamins

\begin{tabular}{|c|c|c|c|c|c|c|c|}
\hline \multirow[b]{2}{*}{ Vitamin } & \multirow[b]{2}{*}{$N$} & \multicolumn{3}{|c|}{ Multiple risk factor adjustment ${ }^{\dagger}$} & \multicolumn{3}{|c|}{$\begin{array}{c}\text { Multiple risk factor adjustment } \\
\text { plus homocysteine }\end{array}$} \\
\hline & & Odds ratio & $95 \% \mathrm{CI}^{*}$ & $P$-value & Odds ratio & $95 \% \mathrm{CI}$ & $P$-value \\
\hline Folate $(\mu \mathrm{g} / \mathrm{L})$ & 1,027 & & & & & & \\
\hline$<2.51$ & & 1.9 & $1.3,2.7$ & 0.001 & 1.5 & $1.0,2.3$ & 0.04 \\
\hline $2.51-4.31$ & & 1.4 & $1.0,2.0$ & 0.08 & 1.3 & $0.9 ; 1.9$ & 0.24 \\
\hline $4.32-7.92$ & & 1.2 & $0.8,1.8$ & 0.28 & 1.2 & $0.8,1.8$ & 0.35 \\
\hline$\geq 7.93$ & & 1.0 & & & 1.0 & & \\
\hline$P_{\text {trend }}$ & & & & $<0.001$ & & & 0.05 \\
\hline Vitamin $B_{12}(\mathrm{ng} / \mathrm{L})$ & 881 & & & & & & \\
\hline$<290$ & & 1.4 & $0.9,2.1$ & 0.11 & 1.2 & $0.8,1.8$ & 0.41 \\
\hline $290-405$ & & 1.4 & $0.9,2.0$ & 0.14 & 1.2 & $0.8,1.8$ & 0.36 \\
\hline $406-572$ & & 1.3 & $0.9,2.0$ & 0.16 & 1.3 & $0.9,1.9$ & 0.24 \\
\hline$\geq 573$ & & 1.0 & & & 1.0 & & \\
\hline$P_{\text {trend }}$ & & & & 0.11 & & & 0.47 \\
\hline Pyridoxal-5'-phosphate (nmol/L) & 967 & & & & & & \\
\hline$<31.91$ & & 1.6 & $1.1,2.4$ & 0.02 & 1.3 & $0.9,2.0$ & 0.15 \\
\hline $31.91-52.19$ & & 1.1 & $0.7,1.6$ & 0.67 & 1.0 & $0.6,1.4$ & 0.80 \\
\hline $52.20-89.80$ & & 1.2 & $0.8,1.7$ & 0.48 & 1.1 & $0.7,1.6$ & 0.71 \\
\hline$\geq 89.81$ & & 1.0 & & & 1.0 & & \\
\hline$P_{\text {trend }}$ & & & & 0.03 & & & 0.23 \\
\hline
\end{tabular}

* CI $=$ confidence interval.

${ }^{\dagger}$ Adjusted for sex, age, total/HDL cholesterol ratio, smoking status, and systolic blood pressure.

${ }^{\ddagger}$ To convert to SI units, multiply folate values by 2.266 to get values in $\mathrm{nmol} / \mathrm{L}$ and vitamin $\mathrm{B}_{12}$ values by 0.7378 to get values in pmol/L.

confidence interval [1.3-2.7]) in the lowest folate quartile and 1.6 (95\% confidence interval [1.1-2.4]) in the lowest pyridoxal $-5^{\prime}$-phosphate quartile. Plasma vitamin $B_{12}$ exhibited a weak association with stenosis $\left(P_{\text {trend }}=0.11\right)$. The OR for stenosis was $1.4(95 \%$ confidence interval [0.9-2.1] in the lowest vitamin $B_{12}$ quartile compared with the highest quartile. Adjustment for homocysteine diminished the strength of plasma vitamin associations, but the elevated prevalence of stenosis in the lowest plasma folate quartile remained evident (OR: 1.5; 95\% confidence interval: 1.0-2.3).

\section{Discussion}

These data suggest an important role for nutrition in homocysteine metabolism. We have demonstrated strong, nonlinear, inverse associations between homocysteine concentrations and plasma concentrations of folate, vitamin $B_{12}$, and vitamin $B_{6}$. We observed that individuals with low levels of each of these vitamins had high plasma homocysteine concentrations, while those with moderate vitamin levels had dramatically lower homocysteine concentrations. Homocysteine levels did not differ substantially between individuals with moderate and high vitamin concentrations.
The results for folate and vitamin $\mathrm{B}_{6}$ intake data are consistent with those for the plasma vitamins. Although it is risky to attribute discrete quantitative values based on this method of dietary assessment [41], it still may be worth noting that homocysteine concentrations were elevated among individuals with folate intakes up to $280 \mu \mathrm{g} / \mathrm{day}$, which is higher than the current RDA of 200 and $180 \mu \mathrm{g} /$ day for adult men and women, and vitamin $B_{6}$ intakes as high as $1.92 \mathrm{mg} /$ day, which is less than the RDA of $2.0 \mathrm{mg} /$ day for men but greater than the RDA of $1.6 \mathrm{mg} /$ day for women.

Adequate levels of all three vitamins may be needed to obtain an optimal homocysteine concentration. Using the index based on levels of all three vitamins, we estimated that approximately twothirds of the cases of elevated homocysteine concentration in this cohort were associated with low or moderate plasma levels of one or more of the three vitamins.

Our data also provide evidence that plasma homocysteine levels are associated with extracranial carotid stenosis in a population-based, elderly cohort. We observed that risk of stenosis $\geq 25 \%$ was increased at homocysteine concentrations previously believed to be normal, based on levels of homocysteine among normative samples. As in our previous analysis, we 
defined elevated plasma homocysteine as concentrations $>14 \mu \mathrm{mol} / \mathrm{L}$ (90th percentile among individuals with apparently adequate folate, vitamin $B_{12}$ and vitamin $B_{6}$ status). Stampfer et al. [46] defined elevated homocysteine as concentrations greater than $15.8 \mu \mathrm{mol} /$ liter (95th percentile among nondiseased control subjects). Joosten et al. [47] defined elevated homocysteine as concentrations greater than $13.9 \mu \mathrm{mol} / \mathrm{L}$ (mean plus two standard deviations among healthy young controls). Genest and coworkers [48] reported 90th and 95th percentile values of 15.0 and $19.0 \mu \mathrm{mol} / \mathrm{L}$ among their normal controls. In the present study we observed that risk of stenosis was elevated at levels of homocysteine between 11.4 and $14.3 \mu \mathrm{mol} / \mathrm{L}$. These data will require us to reconsider the current beliefs regarding standards for elevated homocysteine.

We have also examined the relations between specific nutrition determinants of hyperhomocysteinemia and stenosis in this elderly cohort. We further demonstrated that folate and pyridoxal- 5 -phosphate were linked to stenosis, in large part, due to their regulation of plasma homocysteine levels as indicated by the diminished odds ratios between stenosis and these vitamins after adjustment for homocysteine levels. Although there was some residual association between plasma folate and stenosis after adjustment for homocysteine, the likelihood ratio test statistic would suggest that addition of folate to a model containing homocysteine did not add any significant contribution. It is likely that measurement error and biologic variability in both folate and homocysteine might explain the residual folate association.

We demonstrated that the majority of these elderly individuals with elevated homocysteine concentrations have insufficient status of folate, vitamin $B_{12}$, or vitamin $B_{6}$, and that others have demonstrated that innocuous vitamin supplementation regimens (including folate, $\mathrm{B}_{12}$, and $\mathrm{B}_{6}$ ) effectively lower moderately elevated plasma homocysteine levels to the normal range [10,20,49-54]. Results of our present study provide the rationale for a randomized, controlled trial of the effect of homocysteine-lowering vitamin therapy on vascular disease morbidity and mortality in hyperhomocysteinemic, elderly individuals.

\section{Acknowledgments}

Support for these studies was provided by U.S. Department of Agriculture National Research Initiative Competitive Grants Program No. 92-37200-7582; U.S. Department of Agriculture contract No. 53$3 \mathrm{k} 06-5-10$; National Institutes of Health contract No. N01-HC-38038; National Heart, Lung and
Blood Institute grant No. R01-HL-40423-05; and National Institute of Neurological Disorders and Stroke grant No. 2-R01-NS-17950-12.

\section{References}

1. Ueland PM, Refsum H, Brattstrom L. Plasma homocysteine and cardiovascular disease. In: Francis RBJ (ed) Atherosclerotic Cardiovascular Disease Hemostasis, and Endothelial Function. New York: Marcel Dekker, Inc, 1992, pp 183-236.

2. Ueland PM, Refsum H. Plasma homocysteine, a risk factor for vascular disease: Plasma levels in health, disease, and drug therapy. J Lab Clin Med 114:473-501, 1989.

3. Mudd SH, Levy HL, Skovby F. Disorders of transsulfuration. In: Scriver CR, Beaudet AL, Sly WS, Valle $\mathrm{D}$ (eds) Metabolic Basis of Inberited Disease, 6th ed. New York: McGraw Hill, Inc, 1989, pp 693-734.

4. Kang S-S, Wong PWK, Norusis M. Homocysteinemia due to folate deficiency. Metabolism 36:458-462, 1987.

5. Lin JY, Kang S-S, Zhou J, Wong, PWK. Homocysteinemia in rats induced by folic acid deficiency. Life Sciences 44:319-325, 1989.

6. Brattstrom L, Israelsson B, Lindgarde F, Hultberg B. Higher total plasma homocysteine in vitamin $B_{12}$ deficiency than in heterozygosity for cystathionine $\beta$-synthase deficiency. Metabolism 37:175-178, 1988.

7. Brattstrom LE, Israelsson B, Jeppsson JO, Hultberg BL. Folic acid: An innocuous means to reduce plasma homocysteine. Scan J Clin Lab Invest 48:215-221, 1988.

8. Stabler SP, Marcell PD, Podell ER et al. Elevation of total homocysteine in the serum of patients with cobalamin or folate deficiency detected by capillary gas chromatography-mass spectrometry. $J$ Clin Invest 81 : 466-474, 1988.

9. Lindenbaum J, Healton EB, Savage DG et al. Neuropsychiatric disorders caused by cobalamin deficiency in the absence of anemia or macrocytosis. $N$ Engl $J$ Med 318:1720-1728, 1988.

10. Lindenbaum J, Savage DG, Stabler SP, Allen RH. Diagnosis of cobalamin deficiency: II. Relative sensitivities of serum cobalamin, methylmalonic acid, and total homocysteine concentrations. Am J Hemat 34:99$107,1990$.

11. Park YK, Linkswiler $H$. Effect of vitamin $B_{6}$ depletion in adult man on the excretion of cystathionine and other methionine metabolites. J Nutr 100:110-116, 1970.

12. Smolin LA, Benevenga NJ. Accumulation of homocyst(e)ine in vitamin $B_{6}$ defiency: $A$ model for the study of cystathionine $\beta$-synthase deficiency. J Nutr 112:1264-1272, 1982.

13. Smolin LA, Benevenga NJ. Factors affecting the accumulation of homocyst(e)ine in rats deficient in vitamin B $_{6} . J$ Nutr 114:103-111, 1984.

14. Smolin LA, Benevenga NJ, Berlow S. The use of be- 
taine for the treatment of homocystinuria. $J$ Pediatr 3:467-472, 1981.

15. Smolin LA, Crenshaw TD, Kurtycz D, Benevenga NJ. Homocyst(e)ine Accumulation in pigs fed diets deficient in vitamin B-6: Relationship to atherosclerosis. $J$ Nutr 113:2122-2133, 1983.

16. Finkelstein JD, Chalmers FT. Pyridoxine effects on cystathionine synthase in rat liver. $J$ Nutr 100:467469, 1970.

17. Ubbink JB, Vermaak WJH, van der Merwe A, Becker PJ. Vitamin B-12, vitamin B-6 and folate nutritional status in men with hyperhomocysteinemia. Am J Clin Nutr 57:47-53, 1993.

18. Selhub J, Miller JW. The pathogenesis of homocysteinemia: Interruption of the coordinate regulation by $\mathrm{S}$-adenosylmethionine of the remethylation and transsulfuration of homocysteine. Am J Clin Nutr 55:131-138, 1992.

19. Mudd SH. Homocystinuria and homocysteine metabolism: Selected aspects. In: Nyhan WL (ed) Heritable Disorders of Amino Acid Metabolism. New York: John Wiley \& Sons, Inc, 429-451, 1974.

20. Finkelstein JD, Martin JS. Methionine metabolism in mammals: Distribution of homocysteine between competing pathways. J Biol Chem 259:9508-9513, 1984.

21. Christensen B, Refsum H, Vintermyr O, Ueland PM. Homocysteine export from cells cultured in the presence of physiological or superfluous levels of methionine: Methionine loading of nontransformed, transformed, proliferating, and quiescent cells in culture. J Cell Physiol 146:52-62, 1991.

22. Ueland PM, Refsum H, Male R, Lillehaug JR. Disposition of endogenous homocysteine by mouse fibroblast C3H/10T1/2 CI 8 and the chemically transformed C3H/10T1/2 MCA CI 16 cells following methotrexate exposure. J Natl Canc Inst 77:283-289, 1986.

23. Selhub J, Jacques PF, Wilson PWF, Rush D, Rosenberg IH. Vitamin status and intake as primary determinants of homocysteinemia in an elderly population. JAMA 270:2693-2698, 1993.

24. Selhub J, Jacques PF, Bostom AG et al. Plasma homocysteine and extracranial carotid stenosis in the Framingham Heart Study. N EnglJ Med 332:286-291, 1995.

25. Dawber TR, Moore FE, Mann GV. Coronary heart disease in the Framingham study. Am J Public Health 47 (Suppl):4-24, 1957.

26. McNamara JR, Schaefer EJ. Automated enzymatic standard lipid analyses for plasma and lipoprotein fractions. Clin Chim Acta 166:1-8, 1987.

27. Warnick GR, Benderson J, Albers JJ. Dextransulfate-magnesium precipitation procedure for quantitation of high-density lipoprotein cholesterol. Clin Chem 28:1379-1382, 1982.

28. Araki A, Sako Y. Determination of free and total homocysteine in human plasma by high-performance liquid chromatography with fluorescence detection. J Chromatogr 422:43-52, 1987.

29. Tamura T, Freeberg LE, Cornwell PE. Inhibition by
EDTA of growth of lactobacillus casei in the folate microbiological assay and its reversal by added manganese or iron. Clin Chem 36:1993, 1990.

30. Camp VM, Chipponi J, Faraj BA. Radioenzymatic assay for direct measurement of pyridoxal 5 '-phosphate. Clin Chem 29:642-644, 1983.

31. Willett W. Nutritional Epidemiology. New York: Oxford University Press, 1990, pp 92-126.

32. Jacques PF, Sulsky SI, Sadowski JA, Phillips JCC, Rush D, Willett WC. Comparison of micronutrient intake measured by a dietary questionnaire and biochemical indicators of micronutrient status. Am J Clin Nutr 57:182-89, 1993.

33. Kleinbaum DG, Kupper LL, Muller KE. Applied Regression Analysis and Other Multivariate Methods, 2nd ed. Boston, MA: PWS-Kent Publishing Co, 1988.

34. Willett WC, Sampson LS, Stampfer MJ et al. Reproducibility and validity of a semiquantitative food frequency questionaire. Am J Epidem 122:51-65, 1985.

35. Rothman KJ. Modern Epidemiology. Boston, MA: Little, Brown and Co., 1986.

36. Stampfer MJ, Malinow MR, Willett WC et al. A prospective study of plasma homocyst(e)ine and risk of myocardial infarction in US physicians. JAMA 268: 877-881, 1992.

37. Joosten E, van den Berg A, Riezler $\mathrm{R}$ et al. Metabolic evidence that deficiencies of vitamin B-12 (cobalamin), folate, and vitamin $\mathrm{B}_{6}$ occur commonly in elderly people. Am J Clin Nutr 58:468-476, 1993.

38. Genest JJ, McNamara JR, Salem DN et al. Plasma homocyst(e)ine levels in men with premature coronary artery disease. Journal Amer Coll Cardiol 16:11141119, 1990.

39. Brattstrom L, Israelsson B, Norrving B et al. Impaired homocysteine metabolism in early-onset cerebral and peripheral occlusive arterial disease: Effects of pyridoxine and folic acid treatment. Atberosclerosis 81:51-60, 1990.

40. Dudman NPB, Wilcken DEL, Wang J et al. Disordered methionine/homocysteine metabolism in premature vascular disease: Its occurrence, cofactor therapy, and enzymology. Arterioscler Thromb 13:1253-1260, 1993.

41. Franken DG, Boers GHJ, Blom HJ, Trijbels JMF. Effect of various regimens of vitamin B-6 and folic acid on mild hyperhomocysteinemia in vascular patients. $J$ Inber Metab Dis 17:159-142, 1994.

42. Glueck CJ, Shaw P, Lang JE et al. Evidence that homocysteine is an independent risk factor for atherosclerosis in hyperlipidemic patients. Am J Cardiol 132136, 1995.

43. Lindgren $\mathrm{F}$, Israelsson $\mathrm{B}$, Lindgren $\mathrm{A}$ et al. Plasma homocysteine in acute myocardial infarction: Homocysteine-lowering effect of folic acid. $J$ Intern Med 237:381-388, 1995.

44. Ubbink JB, Vermaak WJH, van der Merwe A et al. Vitamin requirements for the treatment of hyperhomocysteinemia in humans. J Nutr 124:1927-1933, 1994. 